\title{
Structural analysis of multiplate clutch
}

\author{
Sagar Olekar ${ }^{1}$, Kiran Chaudhary $^{2}$, Anil Jadhav $^{3}$, P. Baskar ${ }^{4}$ \\ ${ }^{1,2,3}$ (PG Scholar, School of Mechanical and Building Sciences, VIT University, Vellore, India) \\ ${ }^{4}$ (Professor, School of Mechanical and Building Sciences, VIT University, Vellore, India)
}

\begin{abstract}
Clutch is mechanism which transfers the rotary motion of one shaft to the other shaft when desired. In automobiles friction clutches are widely used in power transmission applications. To transmit maximum torque in friction clutches selection of the friction material is one of the important task.

In this paper, the multi plate clutch is designed by using uniform wear theory. The $3 D$ model of multi plate clutch has been prepared using modeling software Pro/E. The structural analysis is carried out for friction plate by using analysis software Ansys Workbench 14.0. The results for stress, strain, total deformation and for strain energy are obtained. These results are compared for two different friction materials viz. cork and SF001.
\end{abstract}

Keywords: Ansys, clutch, cork, friction plate, SF001

\section{Introduction}

Clutches are designed to transfer maximum torque with minimum heat generation. During engagement and disengagement the two clutch discs has the sliding motion between them. Due to rubbing of the two discs the large amount heat is generated during engagement and disengagement.

The default state of the clutch is engaged that is the connection between engine and gearbox is always "on" unless the driver presses the pedal and disengages it. If the engine is running with clutch engaged and the transmission in neutral, the engine spins the input shaft of the transmission, but no power is transmitted to the wheels.

There are two types of clutch positive contact clutch and friction clutch. Positive clutch transmits large amount of torque without slip but they have certain disadvantages such asthey cannot be engaged at high speeds, max $60 \mathrm{rpm}$ for jaw clutches, and $300 \mathrm{rpm}$ for toothed clutches. Shock develops during engagement at any speed.Require some relative motion in order to engage when both driving and driven shafts are at rest. These drawbacks are overcome in friction clutch hence friction clutch is most widely used in automotive applications.

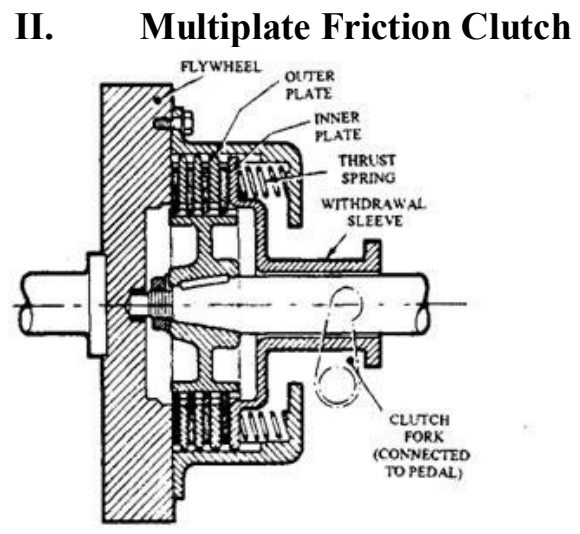

Fig.1 multi plate friction clutch

A simplified multi plate clutch is shown in fig.1.1. It consists of more than one set of pressure plate and friction plate. The one set of plate's slides in grooves on the flywheel and other one slides on splines on the pressure plate hub. Alternate plates belongs to each set. When the pressure is applied to the foot pedal, the pressure is transmitted through the release finger, fork and release bearing. Then the springs are compressed and its moves back the pressure disc thus releasing the clutch plate. Now the clutch is said to be disengaged. At this stage the pressure plate and flywheel are free to rotate with clutch plate stationary. Similarly when the clutch pedal is released, springpressure is fully applied on the clutch plate. The plate is held between flywheel and pressure plate and rotates as a single unit.

Torque capacity of the friction clutch depends upon following factors: Coefficient of friction, the diameter of the friction plate, axial thrust applied by the pressure plate. The diameter of the friction plate is restricted by the size of the clutch. The axial force is limited by the amount force the person can apply on the foot pedal to disengage the clutch. So to transmit maximum torque friction material have adequate coefficient of friction. 


\subsection{Requirements of friction lining:}

1. Relatively high coefficient of friction under operating conditions.

2. Relatively high energy absorption capacity for short periods.

3. Should maintain friction properties over the entire working life.

4. Should withstand high compressive load of pressure plate.

5. Should have adequate shear strength to transmit torque.

6. Good compatibility with base metal over operating temperature range.

7. Should have good heat dissipation capacity.

In this paper the two friction materials are compared viz. conventional cork and SF001. SF001 is a high performance, high friction, nonmetallic composite material containing a high percentage of aramid fiber. It can be considered an alternative to sintered metallic materials and offers many advantages, it will withstand high energy inputs and is suitable for both dry and oil-immersed applications. It is not abrasive to the counter material, silent in operation, it will withstand high pressures. The wear rate is low even at high temperatures.

\section{Methodology}

Power=9.5KW @9000 rpm andTorque=11 Nm @7000 rpm

Friction materials used are cork and SF001.

\begin{tabular}{|c|c|c|}
\hline \multicolumn{3}{|c|}{ Properties of Friction materials } \\
\hline Property & Cork & SF001 \\
\hline Density (Kg/m3) & 180 & 1350 \\
\hline Young's Modulus (N/mm2) & 32 & 7000 \\
\hline Poisson's Ratio & 0.25 & 0.5 \\
\hline Yield Strength (N/mm2) & 1.4 & 68 \\
\hline
\end{tabular}

Material used is cork on steel $\mu=0.25$

Table 1 properties of friction materials

$\mathrm{R} 1$ and $\mathrm{R} 2$ outer and inner radius of friction faces

$\mathrm{R} 1=53 \mathrm{~mm}$ and $\mathrm{r} 2=41 \mathrm{~mm}$

$\mathrm{n}=$ no of pairs of contact surfaces

$\mathrm{n}=\mathrm{n} 1+\mathrm{n} 2-1$

Wheren 1 andn 2 are no of disc on driving and driven shaft

$\mathrm{n} 1=4$ and

$\mathrm{n} 2=4 ; \mathrm{n}=7$

by considering uniform wear theory which states that, wear depends upon intensity of pressure $\mathrm{P}$ and velocity of rubbing which further depend on $\mathrm{R}$, thus for uniform rate of wear $\mathrm{PR}=$ constant.

For uniform wear $\mathrm{R}=(\mathrm{R} 1+\mathrm{R} 2) / 2$

Where $\mathrm{R}=$ mean radius of friction material

$\mathrm{R}=(0.053+0.041) / 2=0.047 \mathrm{~m}$

Torque $(\mathrm{T})=\mu \mathrm{W} \mathrm{R} \mathrm{n}$

Where, $\mu=$ coefficient of friction and $\mathrm{W}=$ Axial load in $\mathrm{N}$

$11=0.25 \times \mathrm{W} \times 0.047 \times 7$

$\mathrm{W}=133.73 \mathrm{~N}$

Now, from uniform wear theory,

$\mathrm{W}=2 \pi \times\left(\mathrm{P}_{\max } \mathrm{x} 2\right) \times(\mathrm{R} 1-\mathrm{R} 2)$

Where, $\mathrm{P}_{\max }=$ maximum pressure between the contacting surfaces

$133.73=2 \pi \times\left(\mathrm{P}_{\max } \times 0.041\right) \times(0.053-0.041)$

$\mathrm{P}_{\max }=43259.73 \mathrm{~N} / \mathrm{m} 2$

Similarly, for another material i.e. SF001 $(\mu=0.5)$ by following the above procedure the values of $\mathrm{W}$ and $\mathrm{P}_{\max }$ are calculated.

$\mathrm{W}=66.86 \mathrm{~N}$

$\mathrm{P}_{\max }=21628.25 \mathrm{~N} / \mathrm{mm} 2$

Following 3D model drawn in Pro/E is used for the analysis. 


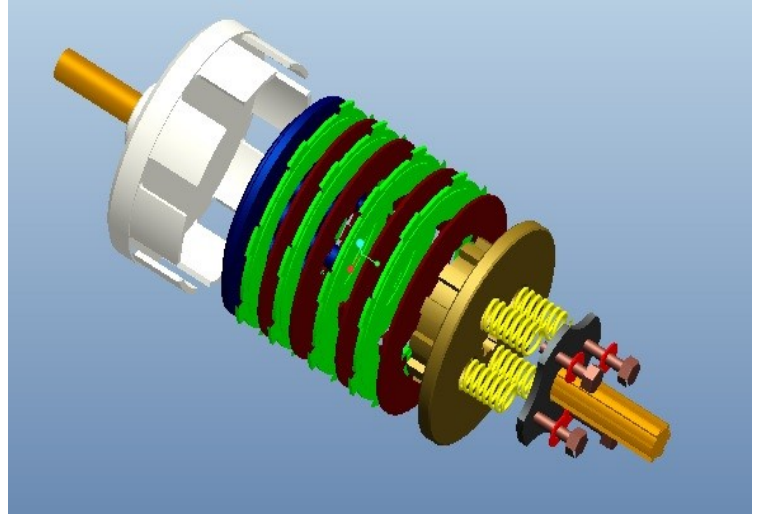

Fig.2 3D model assembly of exploded multi plate clutch

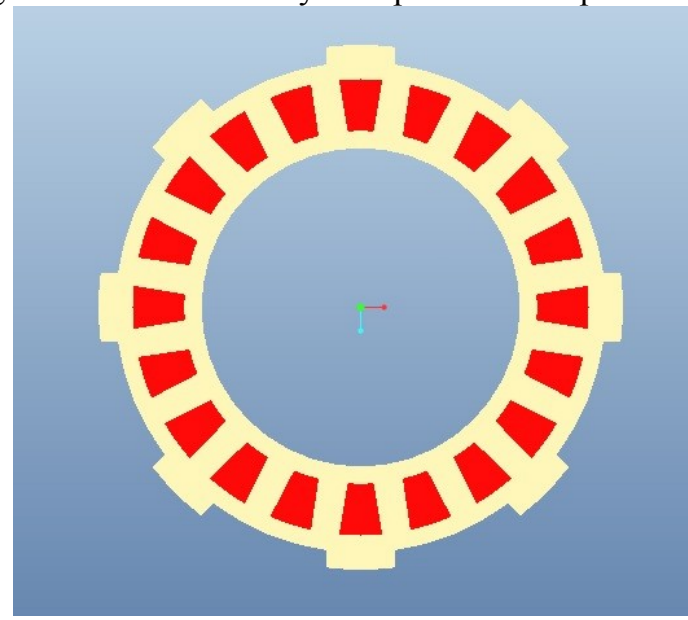

Fig.3 3D model of friction plate

The maximum pressure obtained by calculations is applied on the friction plate and results are obtained in Ansys and stress and deformation values are compared for two different materials.

\section{Results}

4.1 Results obtained by considering cork as a friction material:

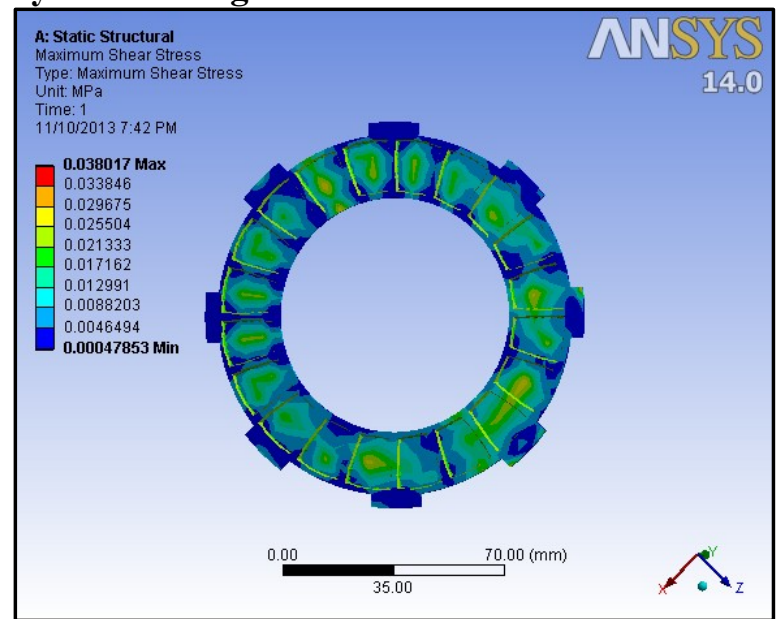

Fig.4 max. shear stress 


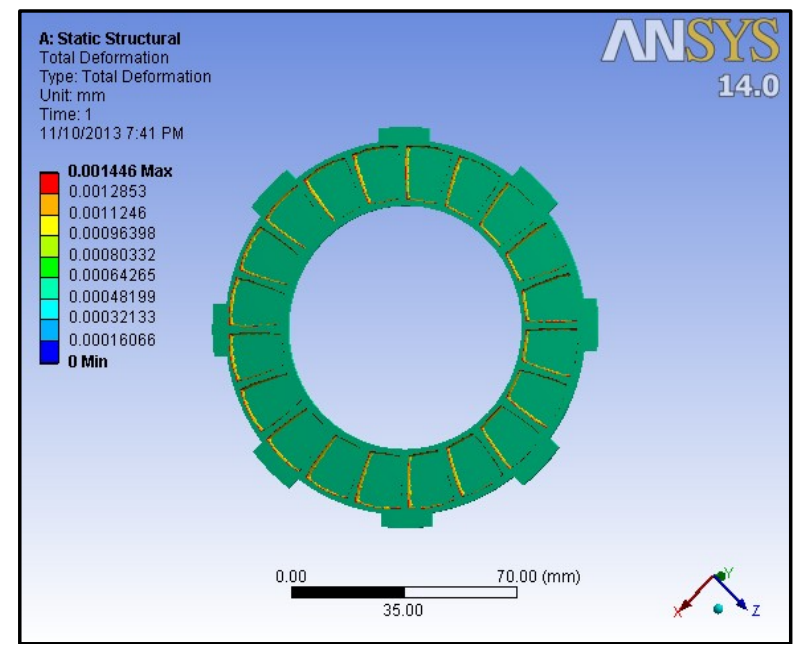

Fig.5 total deformation

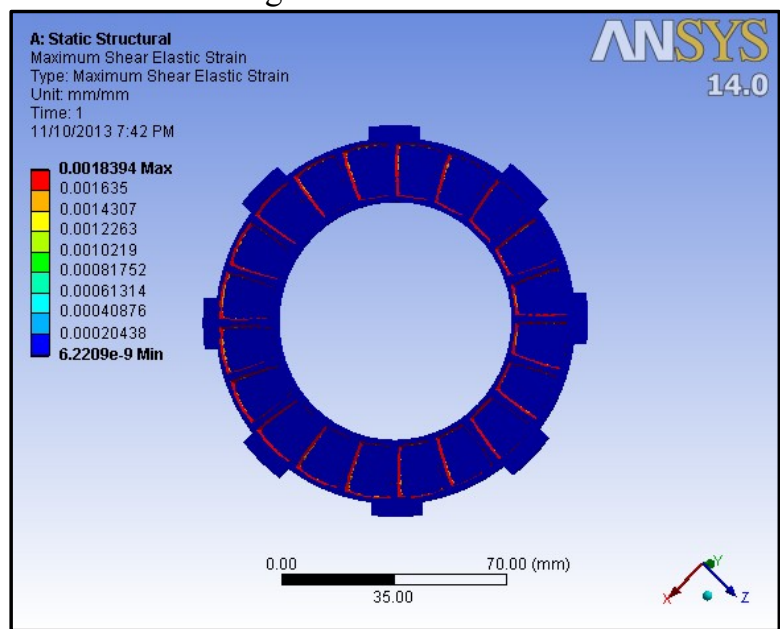

Fig.6 max. shear elastic strain

\subsection{Results obtained by considering SF001 as a friction material:}

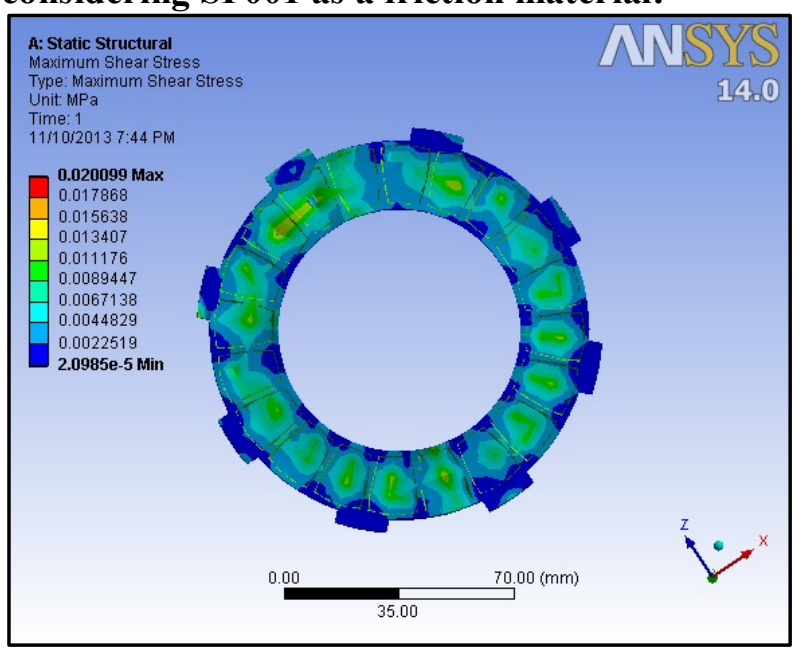

Fig.7 max. shear stress 


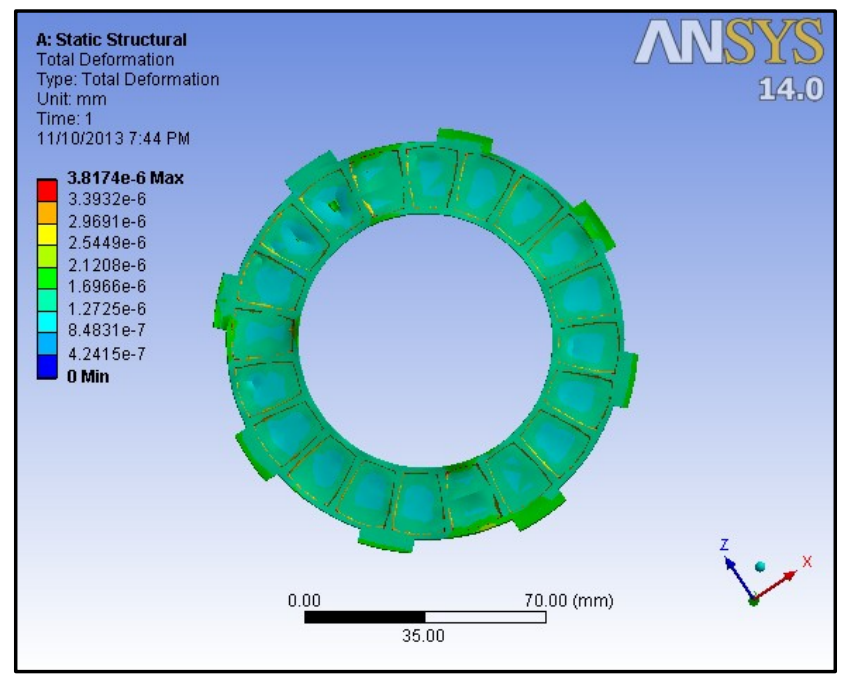

Fig.8 total deformation

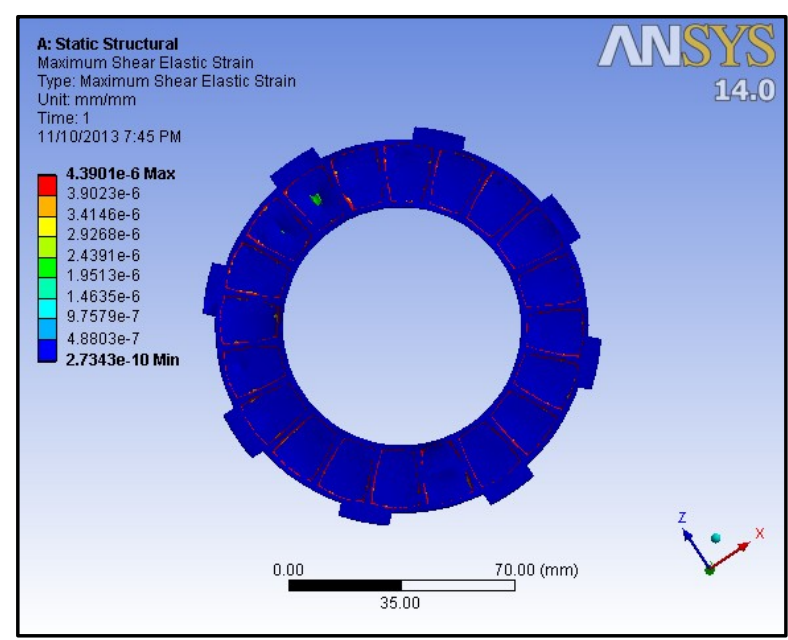

Fig. 1.9 max. shear elastic strain

Maximum shear stress obtained for cork is $0.038017 \mathrm{MPa}$ while for SF001 is $0.020099 \mathrm{MPa}$. Total deformation in cork is obtained as $0.001446 \mathrm{~mm}$ and that in SF001 is $3.82 \mathrm{e}-6 \mathrm{~mm}$ which is very less as compared to cork. Maximum shear elastic strain obtained in cork is 0.0018394 and for SF001 it is 4.39e-6. The results obtained in Ansys are tabulated below.

\begin{tabular}{|c|c|c|}
\hline Property & Cork & SF001 \\
\hline $\begin{array}{c}\text { Max. shear stress } \\
(\mathrm{N} / \mathrm{mm} 2)\end{array}$ & 0.038017 & 0.020099 \\
\hline Total deformation $(\mathrm{mm})$ & 0.001446 & $3.82 \mathrm{E}-06$ \\
\hline $\begin{array}{c}\text { Max. shear elastic strain } \\
(\mathrm{mm} / \mathrm{mm})\end{array}$ & 0.0018394 & $4.39 \mathrm{E}-06$ \\
\hline $\begin{array}{c}\text { Equivalent stress } \\
(\mathrm{N} / \mathrm{mm} 2)\end{array}$ & 0.075834 & 0.038517 \\
\hline Strain Energy $(\mathrm{mJ})$ & $7.25 \mathrm{E}-05$ & $1.79 \mathrm{E}-07$ \\
\hline
\end{tabular}

Table 2 Results

\section{Conclusion}

From the above table2, it is observed that the total deformation, strain energy, shear elastic strain for clutch plate with SF001 as a friction material is less than that of Cork. For same input torque stress developed in clutch plate with friction material SF001is less compared to cork. Hence it is concluded that the clutch plate with friction material SF001 gives better performance than cork.

[1] S .Jaya Kishore, M. Lava Kumar, "Structural Analysis of Multi-Plate Clutch”, International Journal of Computer Trends and Technology (IJCTT) - volume 4 Issue 7-July 2013. 